\title{
Aroma de café: \\ Economía y empresas cafeteras en la Sierra Nevada de Santa Marta
}

\author{
Smell of Coffee: \\ Economy and Coffee Companies in the Sierra Nevada de \\ Santa Marta
}

Joaquin Viloria De La Hoz ${ }^{1}$

\begin{abstract}
Resumen
En este artículo se estudia la economía cafetera de la Sierra Nevada de Santa Marta y la Serranía de Perijá, así como las actividades empresariales que surgieron en torno a esta actividad desde finales del siglo XIX hasta principios del siglo XXI. El estudio muestra los orígenes del cultivo del café en el Caribe colombiano, destacando tres haciendas y varios pioneros de la caficultura regional. Una parte considerable de esa colonización iniciada a finales del siglo XIX en la Sierra Nevada y Serranía de Perijá fue adelantada por empresarios y familias extranjeras, ubicados mayoritariamente en la vertiente Norte de la Sierra Nevada. Haciendas como Jirocasaca, La Victoria y Cincinnati son estudiadas en este artículo con cierta profundidad, así como algunos pioneros del cultivo como Pedro Cothinet, Joaquín de Mier, Francois Dangond, Orlando Flye y las familias Opdenbosch y Weber. Los casos estudiados en este artículo se enmarcan dentro de los postulados teóricos de la historia empresarial (business history y entrepreneurial history), que tienen su origen en la década de 1920 en las universidades de Estados Unidos.
\end{abstract}

Palabras clave: café; empresarios cafeteros; haciendas cafeteras; Sierra Nevada de Santa Marta; Serranía del Perijá.

Tipología: Artículo de investigación

Recibido: 26/03/2019

Evaluado: $27 / 04 / 2019$

Aceptado: 30/04/2019

Disponible en línea: 1/04/2019

Cómo citar este artículo: Viloria De La Hoz, J. (2019). Aproximación histórica a las empresas y la economía cafetera en la Sierra Nevada de Santa Marta. Jangwa Pana, 18 (2), 163-181. Doi:

http://dx.doi.org/10.21676/16574923.2924

\footnotetext{
${ }^{1}$ Doctor en Historia por la Universidad Autónoma de Puebla, México. Gerente del Centro Cultural del Banco de la República en Santa Marta y profesor catedrático de la Universidad del Magdalena.
} 


\begin{abstract}
In this article are studied the coffee economy of the Sierra Nevada de Santa Marta and Serrania del Perijá, as well as the business activities that emerged around this activity, from late nineteenth century to early twentyfirst century. The study shows the origins of coffee growing in the Colombian Caribbean, highlighting three farms and several pioneers of regional coffee. A considerable part of that colonization that started in the late nineteenth century in the Sierra Nevada and Serrania del Perijá, was advanced by foreign businessmen and families, located mostly on the northern slope of the Sierra Nevada. Plantations such as Jirocasaca, La Victoria and Cincinnati are studied in this article with some depth, as well as some pioneers of cultivation such as Pedro Cothinet, Joaquín de Mier, Francois Dangond, Orlando Flye and the Opdenbosch and Weber families. The cases studied in this article are framed within the theoretical postulates of business history and entrepreneurial history, which have their origin in the 1920s in the universities of the United States.
\end{abstract}

Keywords: Coffee; Coffee Businessmen; Coffee plantations; Sierra Nevada de Santa Marta; Serrania de Perijá.

\section{Introducción}

$\mathrm{E}^{\mathrm{n}}$ este artículo se estudia la economía y las actividades empresariales surgidas de la colonización cafetera adelantada en la Sierra Nevada de Santa Marta y en la Serranía del Perijá. La investigación se concentra en las dos últimas décadas del siglo XIX y llega hasta las dos primeras décadas del siglo XXI. Este estudio busca mostrar los orígenes del cultivo del café en esta zona del país, destacando tres haciendas en funcionamiento en pleno siglo XXI (Jirocasaca, La Victoria y Cincinnati) y tres de los pioneros de la caficultura regional (Pedro Cothinet, Joaquín de Mier y Francois Dangond).

Gran parte de esa colonización cafetera, iniciada a finales del siglo XIX en la Sierra Nevada y en la Serranía del Perijá, fue impulsada por empresarios extranjeros que supieron aprovechar fortalezas como la ubicación estratégica frente al mar Caribe, así como la calidad y el tamaño del grano producido en esa zona del país. Los casos estudiados en este artículo se enmarcan en los postulados teóricos de la historia empresarial (business history y entrepreneurial history), que tienen su origen en la década de 1920 en las universidades de Estados Unidos. La historia de los empresarios se concentra en el estudio de los emprendedores, de aquellas personas que están atentas a las oportunidades (oportunistas) para crear empresa, por lo que es necesario entender sus motivaciones, su comportamiento y su racionalidad (Torres, 2003; Marichal, 2003).

Lo planteado en este artículo se publicó de manera preliminar hace dos décadas (Viloria, 1998 y 1998A), período durante el cual el artículo ha sido corregido y actualizado.

\section{Antecedentes del café en la Sierra Nevada}

A mediados del siglo XVIII se informa de los primeros cultivos de café en la Sierra Nevada de Santa Marta. En el período de la República, se dan las primeras recomendaciones e intentos colonizadores fallidos en la Sierra Nevada: Joaquín Acosta (1845 y 1851), Joaquín de Mier (1825 y 1855), Eliséo Reclus (1855) y Jean Elie Gauguet. En 1873, el gobierno colombiano concedió a Gauguet 2.500 hectáreas en la Sierra Nevada, para ser colonizadas por cerca de 1.200 colonos franceses. Las enfermedades tropicales frustraron este nuevo intento colonizador (Krogzemis, 1967: 132). Más tarde, la Sierra Nevada fue estudiada por más de 150 
exploradores y científicos (Fundación Pro-Sierra Nevada de Santa Marta, 1994).

La fiebre colonizadora llevó a que el estado soberano del Magdalena cediera en 1871 al Gobierno Central los "Territorios de la Nevada y los Motilones", para efectos de emprender programas de poblamiento con colonos europeos. De acuerdo con Guhl (1950: 120), la colonización espontánea emprendida por familias extranjeras o andinas fue un poco más exitosa que la dirigida por el Estado a través de sus empresas colonizadoras.

A nivel institucional, se ha contado con la presencia de la Federación Nacional de Cafeteros de Colombia, desde su creación en 1927. Inicialmente se tuvo el Comité Departamental de Cafeteros del Magdalena, que funciona desde la década de 1930, y a partir de 1977 se creó un nuevo Comité de Cafeteros en la región Sierra Nevada-Perijá: el de Cesar y La Guajira.

En 2018, el cultivo de café en la Sierra Nevada y en la Serranía del Perijá ocupaba 51.000 hectáreas, en una zona comprendida entre 700 y $1.500 \mathrm{msnm}$. La zona cafetera del Magdalena abarca los municipios de Santa Marta, Ciénaga, Fundación y Aracataca, con un área sembrada de 20.000 hectáreas de café, en el que Ciénaga es el municipio cafetero por excelencia, con más del $50 \%$ del área cultivada, seguido de Santa Marta. El Magdalena cuenta con 5.233 fincas y 4.812 familias cafeteras. En el año 2018 se estimó una producción de 13.000.000 de kilogramos de café pergamino seco (Comité Departamental de Cafeteros del Magdalena, 2019). En los departamentos de Cesar y La Guajira se tienen sembradas 31.000 hectáreas, distribuidas en 29 municipios, de los cuales 19 están en el Cesar y los otros 10 en La Guajira. En los dos departamentos hay 10.409 fincas y 9.939 familias cafeteras (Comité Departamental de Cafeteros Cesar-Guajira, 2019). Pueblo Bello, Urumita y Villanueva son los municipios con mayores áreas sembradas y producción cafetera en estos dos departamentos del Caribe.
Por otro lado, a nivel de instituciones de apoyo se cuenta con la Cooperativa Cafetera de la Costa - Caficosta (2018), patrocinada por la Federación Nacional de Cafeteros de Colombia. La Cooperativa fue constituida en el 2007 por 91 asociados cafeteros y a 2018 contaba con 2.600 afiliados en cuatro departamentos de la región Caribe: Magdalena, Cesar, La Guajira y Bolívar. En el 2018, la Cooperativa compró cerca de 6.400.000 kilogramos de café pergamino seco. También ejercen presencia en la zona cafetera tres Corporaciones Autónomas Regionales (Corpamag, Corpocesar y Corpoguajira), 33 municipios con jurisdicción sobre la Sierra Nevada y la Serranía del Perijá, y varios resguardos indígenas.

\section{Pioneros de la caficultura regional: Cothinet, De Mier y Dangond}

Los primeros arbustos de café fueron traídos al continente americano entre 1714 y 1720 por holandeses y franceses, quienes procedieron a plantarlos en sus colonias de Guayana y Martinica, respectivamente, y luego su siembra se extendió por el resto del continente (Banco de la República, 1964). En 1778, el gobernador de la provincia de Santa Marta y Río Hacha informaba sobre la existencia de cafetos en la Sierra Nevada de Santa Marta, pero dispersos y sin mantenimiento (De Narváez y De Pombo, 1965 , p. 30). A pesar de que a menudo se sostiene que los cultivos comerciales de café se iniciaron en la Provincia de Cúcuta hacia 1808, la evidencia demuestra que en San Carlos de la Fundación y Minca se cultivó comercialmente café por lo menos desde finales del siglo XVIII.

Uno de los primeros agricultores que en la Nueva Granada sembró café con fines comerciales fue el francés Pedro Cothinet. En 1793, informaba Cothinet al gobernador de la provincia de Santa Marta lo siguiente:

Mis proyectos de cafetería y cacaual juntamente con la apertura del río (Fundación) han excitado tal emulación 
entre los vecinos que empiezan a pleitar y codiciar las tierras... Encargo a Guillermo Vester, portador de la presente, comprarme tres cargas de cacao para sembrar. Si V.S. ha conseguido el café nos hará el favor en hacerle entrega. Yo mismo cuidaré los semilleros, como lo hago diariamente de un poco de café, pero algo viejo. (Blanco Barros, 1996, p. 33)

En 1818, Pedro Cothinet tenía una hacienda cerca de la Fundación, en la que tenía cultivado cerca de 17.000 árboles de cacao y 4.000 arbustos de café ${ }^{2}$.

También de finales del siglo XVIII es la hacienda Minca, una de las grandes plantaciones de caña de azúcar y café. Entre 1800 y 1818, la familia Oligós Díaz Granados empezó a desarrollar los cafetales de Minca, reconocida como una las primeras haciendas cafetaleras de Colombia $^{3}$. De acuerdo con un escrito de 1828 , Minca era: “...un extenso cafetal cuya creación se remonta muchos años atrás a la época de la dominación española" (Le Moyne, 1969, p. 25). A partir de 1838, Minca fue propiedad de Don Joaquín de Mier y Benítez, el comerciante más próspero de la provincia de Santa Marta durante gran parte del siglo XIX. La escasez de mano de obra a partir de la segunda década del siglo XIX, llevó a De Mier a plantear en 1825 un ambicioso plan de inmigración y colonización de la Sierra Nevada de Santa Marta. Este proyecto consistía en colonizar cerca de 200.000 fanegadas de baldíos nacionales, para instalar allí una colonia agrícola integrada inicialmente por 60 familias extranjeras, dedicadas básicamente al cultivo del café (De Mier, 1975, p. 33).

Ante la negativa del Congreso de la República de adjudicar a la empresa colonizadora los baldíos solicitados, y la gravedad que representaba la escasez de trabajadores agrícolas por la abolición de la esclavitud en 1850,

2 Archivo Histórico del Magdalena Grande - AHMG, Gobernación de la Provincia de Santa Marta, Juzgado de Bienes de Difuntos, Causa: "Mortuoria de don Pedro Cothiné”, 1817-1819, folios 356-450.
Joaquín de Mier decidió contratar en Italia cincuenta agricultores, con quienes esperaba transformar nuevamente a Minca en un próspero cafetal. Infortunadamente para De Mier, luego de tres meses de permanencia en la plantación, los italianos abandonaron Minca para establecerse en el antiguo pueblo de San Carlos de la Fundación (Reclus, 1992, p. 133).

Además de Pedro Cothinet y Joaquín de Mier, otro cultivador de café en la primera mitad del siglo XIX fue el francés Francois Dangond, quien se instaló en Villanueva (Dangond, 1990). A finales de esa década se inició como agricultor y, para 1855, había logrado cultivar en su finca "El Toro", ubicada en la Serranía del Perijá o Sierra Negra, ochenta hectáreas de terrenos y sembrar más de cien mil pies de café.

Sobre este agricultor dice Reclus (1992):

...lo que hizo para sí es poca cosa comparado con el impulso que le dio al país entero. Abrió anchos caminos, construyó puentes, hizo acueductos... A virtud de todo esto, una docena de caballeros de Villanueva, Urumita y ValleDupar... han hecho desmontar otras porciones de Sierra-Negra y plantado más de seiscientas mil matas de café... (p. 197)

que producían como mínimo 300.000 kilogramos de café cereza.

En la vertiente norte, la expansión cafetera se inició en la década de 1890 con la llegada de exploradores y comerciantes de origen europeo $\mathrm{y}$ norteamericano, quienes tomaron como modelo las únicas dos plantaciones cafeteras de la Sierra: Minca y Jirocasaca. Con respecto a Minca se sabe que desde principios del siglo XIX perteneció a Pablo Oligós y a su esposa Ana Teresa Díaz Granados. Luego fue propiedad de Manuel Ujueta, Juan de Vengoechea, José María

\footnotetext{
${ }^{3}$ AHMG, Notaría Primera de Santa Marta, Testamento de don Pablo Oligós y nombramiento de su albacea doña Ana Teresa Díaz Granados de Oligós, febrero 27 de 1817.
} 
del Castillo, Martín y Manuel Avendaño, y estos últimos se la vendieron a Joaquín de Mier en 1838. En 1892, Manuel Julián de Mier vendió Minca a su hijo José María Leiva, con una extensión de diez caballerías de tierra, de las cuales catorce cabuyas tenían cultivos de café ${ }^{4}$.

Todavía en 1925 Minca pertenecía a Leiva, quien tenía sembrados cerca de 100.000 cafetos (Monsalve, 1927). Pero, a finales de la década del treinta, se empezó a sustituir por caña de azúcar, siendo el final de la histórica hacienda cafetera. En 1943, Leiva le vendió a los hermanos Dávila Riascos 64 hectáreas que serían convertidas en la hacienda de caña "Arimaca"5 y, en la misma década, los miembros una familia originaria de Santander, los Balaguera, invadieron y luego negociaron con Leiva un globo de terreno de 125 hectáreas, de donde surgiría el caserío de Minca ${ }^{6}$.

\section{La configuración del Cinturón Cafetero}

\section{A. Colonización de la vertiente norte}

Los cultivos comerciales de café en la Costa Caribe colombiana están concentrados en la Sierra Nevada de Santa Marta y en la Serranía del Perijá en un $98 \%$ del producto cafetero regional. Entre1896 y 1920 la vertiente norte de la Sierra Nevada se convirtió de nuevo en atractiva para explotaciones cafeteras, impulsadas en su mayoría por empresarios de origen extranjero. En este período se consolidó la caficultura comercial del Magdalena a partir de haciendas como Minca, Jirocasaca, La Victoria, Cincinnati y Vista de Nieve. En 1895, empresarios ingleses empezaron a estructurar "El Recuerdo" y, en 1896, los hermanos Dávila Pumarejo fundaron la hacienda "María Teresa". En esa época, Manuel Dávila fue designado como vicepresidente de la Sociedad de Agricultores de Colombia (SAC) y miembro del Comité Nacional de Cafeteros en la década

4 AHMG, Notaría Primera de Santa Marta, Escritura Pública $\mathrm{N}^{\circ} 38,23$ de mayo de 1892.

5 AHMG, Notaría Segunda de Santa Marta, Escritura Pública $\mathrm{N}^{\circ}$ 41, 26 de febrero de 1943. de 1930 (Sociedad de Agricultores de Colombia - SAC, 1924, p. 51).

De 1897 data la fundación de la Onaca Coffee Plantation, hacienda cafetera de la empresa escocesa Kunhardt \& Co., donde trabajaban holandeses, jamaiquinos y portorriqueños (Posada Carbó, 1993, p. 156). Otras haciendas de gran producción a principios de siglo eran "Manzanares", de José Ignacio Díaz-Granados; "Las Nubes" y "Mendiguaca", de Francisco Luis Olarte; "San Isidro", de la familia Travecedo; "Donama", de Pablo García, quien compraría posteriormente "El Recuerdo"; "Las Mercedes", de Ramón Goenaga y Manuel Díaz Granados Pumarejo; "Medellín”, de la Compañía Agrícola de Santa Marta; y “San José”, de César Campo.

\section{B. Colonización de la vertiente suroriental y de la Serranía del Perijá}

A mediados del siglo XIX se inició la colonización de la Serranía de Perijá y la vertiente suroriental de la Sierra Nevada, encabezada por el ciudadano francés Francois Dangond, los hermanos Cotes, los hermanos Mestre, así como por las familias Villazón y Baute. Hacia 1920, en los municipios de Valledupar y Villanueva sobresalían fincas como La Carolina, La Sagrada, La María, La Gruta, La Margarita, El Porvenir, La Legua, San Esteban y Sierra Negra. Entre 1924 y 1937 llegaron a la región de Pueblo Bello por lo menos 50 personas de origen alemán, con la intención de establecer explotaciones agropecuarias en esta zona ubicada entre los 1.000 y 1.500 msnm. Al fracasar como agricultores, la mayoría de los alemanes se radicaron en Barranquilla, algunos lograron regresar a su país y otros murieron en el intento colonizador (Friede, 1963).

Durante la época de la violencia política en Colombia (décadas de 1940 y 1950) comenzaron

${ }^{6}$ Entrevistas con los señores Jesús Balaguera (14 de mayo de 1997) y Delfín Balaguera Jr. (15 de mayo de 1997), en Santa Marta. 
a llegar a la región familias del interior del país, en su mayoría de los Santanderes, Tolima, Antioquia y Valle del Cauca. A nivel de asentamientos humanos, en 1925 las poblaciones cafeteras eran Pueblo Bello y Atánquez, municipio de Valledupar, en la Sierra Nevada de Santa Marta, y Villanueva, Urumita, El Molino y Espíritu Santo, en la Serranía del Perijá.

Para 1950, la colonización andina impulsó nuevos cultivos de café, dando origen a corregimientos y caseríos como Chimila y Nuevo Colón en la Sierra Nevada, así como San José de Oriente, Medialuna, La Victoria de San Isidro, Conejo y San Pedro, en la Serranía del Perijá.

\section{Colonización de la vertiente occidental}

Los primeros cultivos de café en esta zona de la Sierra Nevada fueron impulsados por el ciudadano francés Pedro Cothinet desde finales del siglo XVIII. En 1913, un explorador reportó que: “...A unos diez kilómetros agua arriba de Buenos Aires, en la orilla del río, hay una plantacioncita de café fundada hace muchos años por un súbdito inglés de apellido Cambel (sic)" (Thevernin, 1924, p. 231). Pero la colonización cafetera, como tal, llegó mucho más tarde: en la década del cuarenta del siglo XX.

Hacia 1924 se inició una primera colonización espontánea con campesinos de regiones andinas y, para 1950, los asentamientos de San Luis, El Mico y San Andrés, actual San Pedro de la Sierra, concentraban en total unos 500 colonos. Al respecto, dice Guhl (1950) que

Los principales cultivos de esta zona son el café en la parte baja que representa el único negocio y producto de exportación de los colonos, aunque podrían exportar muchos otros productos porque el rendimiento que da la tierra de esta región es tan abundante como no lo hemos visto en muchas otras partes de la república. (p. 120)

Pero, como siempre, la limitante en este caso fue y continúa siendo las vías de comunicación.

En la región de San Pedro de la Sierra, antiguo poblado indígena San Andrés de los Kogis, el café se empezó a explotar de manera comercial en la década de 1940, con la llegada de empresarios agrícolas como Alfonso CampoSerrano Riascos, Jorge Sumbattoff, Julio Dangond, Mateo Vives, la familia Fernández de Castro y Celio Villalba. Este empresario santandereano estaba radicado en Barranquilla y era propietario de la tostadora "Café Almendra Tropical". Dangond y Sumbattoff fueron los encargados de conseguir las semillas de café en la hacienda Jirocasaca, que diseminaron por toda la zona de San Pedro de la Sierra. El entusiasmo por el café fue tal que, para 1947, en la región existían por lo menos 20 fincas cafeteras, que empezaron a ser vistas en la Costa Caribe como señal inequívoca de prosperidad económica. Los trabajadores contratados eran oriundos, en su mayoría, de los Santanderes y Tolima, municipios de Ocaña, San Vicente de Chucurí, Anzoátegui y El Líbano.

La colonización en la cuenca media del río Sevilla fue iniciada por Edmundo Abello y otros empresarios samarios a mediados de la década de 1950. De esta época datan las primeras fincas cafeteras dentro de la que se destaca "La Conquista", propiedad de Abello. En 1960, Pablo Solano Dávila compró "La California", finca que se convertiría en modelo para otras grandes propiedades como "La Navidad", del mismo dueño, y "Montería", de Carlos Lacouture. La hacienda California llegó a tener más de 2.000 hectáreas en diferentes pisos térmicos, en las que había potreros con pasto, monte bajo, bosques secundarios y cerca de 200 hectáreas en café.

La carretera a Palmor fue construida a mediados de la década de 1960 por el propietario de la hacienda "California", quien entendió la obra 
como una forma de hacer más competitivo su producto de exportación. El dinamismo cafetero de Palmor terminó por desplazar a San Pedro de la Sierra a nivel de producción, y convertir a Ciénaga en el municipio cafetero del Magdalena a partir del Censo Cafetero 1980-1981. Luego de establecidas las poblaciones de San Pedro de la Sierra en 1957 y Palmor en 1967, la colonización más reciente en la vertiente occidental se adelantó en la parte alta del municipio de Fundación, cuencas de los ríos Aracataca y Fundación.

\section{Aproximación a tres haciendas cafeteras}

\section{A. Hacienda Cincinnati}

Los fundadores de la hacienda Cincinnati, pioneros de la caficultura comercial en el Magdalena, llegaron a Colombia en 1889. El ingeniero Orlando Flye llegó a Barranquilla para instalar el servicio de teléfono y telégrafo en la ciudad. En 1892, Flye fue contratado por el gobernador del Magdalena, Ramón Goenaga, para construir una microcentral hidroeléctrica en Santa Marta. Esta infraestructura se convertiría en la primera planta eléctrica del país (El Espectador, 1969, p. 3A).

Pero el futuro de este norteamericano y de su esposa Eva no estaba en el ejercicio de la ingeniería, sino en la agricultura. En los años finales del siglo XIX, envió a Estados Unidos unas muestras de café de la Sierra Nevada de Santa Marta, de donde le confirmaron la excelente calidad y aroma del grano. Con este concepto positivo, Flye inició en 1893 la exploración de los terrenos y las altitudes más adecuadas para sembrar el café en la Sierra Nevada (Flye, 1935).

En 1897, Orlando Flye fue contratado por William S. Crane, quien tenía la misión de organizar la hacienda La Victoria de la Libano Coffee Company. En estas exploraciones, por el

\footnotetext{
${ }^{7}$ Entrevista realizada a Beatriz Flye de Mitchell y Paulina Flye de Escribano el día 20 de abril de 1997, Santa Marta.
}

método de prueba y error, llegó al sitio apto para adelantar la caficultura en la Sierra Nevada y sembró en 1898 los primeros arbustos de la hacienda Cincinnati. La hacienda en su conjunto llegó a tener 2.700 hectáreas entre los 500 y 2750 $\mathrm{msnm}^{7}$.

En 1917, algunos campesinos santandereanos llegaron hasta la ciudad de Santa Marta con la intención de viajar a Cuba. Ante los inconvenientes para viajar, estos campesinos se quedaron trabajando en Santa Marta, aunque seguían con la ilusión de viajar a Cuba para trabajar en los cañaduzales, cosa que nunca hicieron. Así, los Balaguera, Reátiga, Becerra, Pineda y Cucunubá, entre otros, empezaron a trabajar en la hacienda Vista Nieve, propiedad de Melbourne Armstrong Carriker, ornitólogo norteamericano casado con una hija de Orlando Flye (Carriker, 2002) ${ }^{8}$. En esos mismos años, Orlando Flye contrató a 25 familias campesinas de Puerto Rico, con experiencia en la recolección de café, para trabajar en su finca cafetera. En época de cosecha, la hacienda contrataba cerca de 800 recolectores, mientras los trabajadores permanentes podían ser entre 60 y 80 .

Orlando Flye y su hacienda cafetera se convirtieron en un referente en la economía cafetera del Magdalena: construyó caminos, instaló puentes y una microcentral hidroeléctrica, entre otras obras. Además, desde los primeros años del siglo XX empezó a exportar café a Europa. Su laboriosidad fue objeto de admiración en el país y demostró "ser un digno representante del modelo ideal del sueño americano: tuvo una constante ética por el trabajo" (Molano, 1988, p. 32). Por sus labores sociales y cívicas, los esposos Orlando y Eva Flye fueron condecorados por el Concejo Municipal de Santa Marta en 1933 y fueron declarados ciudadanos ilustres e hijos adoptivos de la ciudad (Cincinnati Coffee Company, s.f., p. 10).

\footnotetext{
${ }^{8}$ Entrevista con Jesús y Delfín Balaguera, mayo 14 de 1997, Santa Marta.
} 
En 1920, Orlando Flye asistió como delegado del departamento del Magdalena a la sesión inaugural del Primer Congreso Nacional de Cafeteros. Este encuentro fue convocado en Bogotá por la Sociedad de Agricultores de Colombia - SAC. Los otros dos delegados del Magdalena fueron Pedro Manuel Dávila Pumarejo, propietario de la hacienda María Teresa y José Ignacio Díaz Granados, de la hacienda Manzanares. Siete años después, en 1927, se reunió en Medellín el Segundo Congreso Nacional de Cafeteros de Colombia y, a través del Acuerdo $\mathrm{N}^{\circ}$ 2, se decidió organizar la Federación Nacional de Cafeteros de Colombia. No hay evidencia de la presencia de cafeteros del Magdalena en este Segundo Congreso ${ }^{9}$.

Flye fue cónsul de EE.UU. en Santa Marta durante varios años. Durante ese tiempo impulsó la idea de recibir expediciones y científicos norteamericanos interesados en investigar sobre flora, fauna y arqueología de la Sierra Nevada ${ }^{10}$. En la lista de estos científicos se destacaron el ornitólogo M.A. Carriker, del Carnegie Museum; la expedición de la Universidad de Michigan de A. Ruthven, F.M. Gaige y A.S Pearse; el geógrafo G. Taylor, y otros científicos como Rehn, Link y Hall.

Para 1925, Cincinnati ya contaba con 500.000 árboles de café, convirtiéndose en la hacienda más grande de la región, junto a Jirocasaca (Monsalve, 1927, p. 455). Sus 270 hectáreas producían cerca de 180 toneladas de café pergamino por cosecha. Para 1932, esta plantación tenía sembrados 700.000 cafetos y contaba además con 400 hectáreas en pastos artificiales y cerca de 250 cabezas de ganado vacuno (Flye, 1935, p. 28).

\section{Cuadro 1}

Producción de la hacienda Cincinnati, 1925 y 1932

\begin{tabular}{|c|r|r|r|r|r|}
\hline Año & No. cafetos & No. ha. & \# árboles/ha. & Prod. kg/ha & Prod. kg. \\
\hline 1925 & 500.000 & 270 & 1850 & 650 & 175.500 \\
\hline 1932 & 700.000 & 350 & 2000 & 500 & 175.000 \\
\hline
\end{tabular}

Fuente: Cálculos del autor con base en datos de Monsalve (1927) y Flye (1935).

Como la mayoría de las grandes haciendas cafeteras ubicadas en la Sierra Nevada de Santa Marta, Cincinnati fue concebida como una empresa autosuficiente en muchos aspectos, debido a su aislamiento de Santa Marta. Por esta condición, en la época anterior al Banco de la República, creado en 1923, cada hacienda tenía su propia moneda de circulación interna, para facilitar las transacciones entre los propietarios y sus trabajadores.

De igual forma, ante la mala calidad de las vías de acceso, los hijos de los cafeteros no podían trasladarse hasta Santa Marta para recibir sus clases. Esto llevó a que los esposos Flye se

\footnotetext{
${ }^{9}$ En la foto oficial del Segundo Congreso Nacional de Cafeteros, tomada en Medellín el 21 de junio de 1927, aparecen 29 delegados de diferentes zonas cafeteras del país, ninguno de los cuales representa a los cafeteros del departamento del Magdalena (Chalarca, 1998: 108).
}

idearan un modelo para que sus hijos recibieran educación de calidad: contratar en Estados Unidos tutoras para que educaran a los niños de la familia, siendo la más destacada Mary Boardman, quien estuvo en la hacienda Cincinnati en los primeros años del siglo XX. Además de su trabajo como institutriz, Mary escribió una novela romántica sobre su estancia en la Sierra Nevada y las plantaciones de café de la familia Flye (Boardman, 1908).

En síntesis, las grandes haciendas cafeteras de la Sierra Nevada como Cincinnati, Jirocasaca, Onaca y La Victoria, se caracterizaron por ser empresas integrales desde finales del siglo XIX,

\footnotetext{
${ }^{10}$ De acuerdo con Beatriz Flye, estos científicos debían realizar dos actividades: en la mañana hacían sus actividades de recolección y reconocimiento. Por la tarde se convertían en tutores de los niños Flye.
} 
en donde no solo producían y beneficiaban el café, sino que así mismo trillaban, tostaban, empacaban y exportaban el producto desde Santa Marta al mercado de Europa.

Orlando Flye murió en 1937 y la dirección de la hacienda quedó en manos de su hijo William ${ }^{11}$. Esta fue una etapa de modernización en diferentes aspectos: en la década de 1940 terminó de construir la carretera hasta la propia hacienda y construyó varios carreteables al interior de la finca, por lo que el jeep se convirtió en la máquina ideal para transportar el café dentro y fuera de la unidad productiva. Su ética y capacidad de trabajo fue reconocida a nivel departamental y nacional. Esto llevó a que en 1957 fuera designado como segundo vicepresidente del XIX Congreso Nacional Cafetero y que la Sociedad de Agricultores de Colombia (SAC) le otorgara en 1964 la Gran Cruz del Mérito Agrícola.

Pero no todo fue éxitos y reconocimientos. En 1964, William Flye se enfrentó a la expropiación de 974 hectáreas por parte del Incora. Así mismo, la familia Flye parceló 486 hectáreas entre sus trabajadores (Molano, 1988, p. 37). El fin del período modernizador ocurrió en los años setentas, cuando se expandieron de manera descontrolada los cultivos de marihuana por las tres vertientes de la Sierra Nevada. La bonanza marimbera generó delincuencia, deforestación y competencia por mano de obra, pagando mayores salarios que los cafeteros, los bananeros, los arroceros y los palmeros. En el caso del café, esta diferencia llegó a ser de 10 a 1, lo que acentuó aún más la crisis cafetera (Molano, 1988, p. 38).

En 1972 murió William Flye Blanot, quien logró consolidar la producción cafetera de la hacienda Cincinnati, establecida por sus padres desde finales del siglo XIX. En medio de la inseguridad y la falta de brazos para recoger el café, en estos años también murió Orlando Flye, quedando su hermana Beatriz sola en la

11 William Flye Blanot nació en Santa Marta en el año 1900 y murió en 1972. Se casó con Beatriz Salzedo administración de la hacienda. Este cúmulo de acontecimientos negativos obligó a los hermanos Flye Salzedo que sobrevivían, William, Paulina y Beatriz, a vender en 1984 la hacienda Cincinnati a la familia Caballero Aduén.

Después de casi un siglo de haber sido fundada por Orlando Flye y su esposa Eva Blanot, Cincinnati pasó de ser la hacienda cafetera más emblemática de la Sierra Nevada a convertirse en una finca de cafetales abandonados. A partir de ese momento, se presentó una baja considerable en la producción cafetera de la hacienda. Los nuevos propietarios fueron absentistas, con otros intereses económicos en la región, por lo que prestaban poca atención a los cultivos de café. Los Caballero Aduén vendieron Cincinnati a los hermanos Zúñiga Caballero: ninguna de estas dos familias tenía tradición cafetera y sus intereses económicos estaban en otras actividades económicas, por lo que los cafetales continuaron deteriorándose y la producción cayó a los niveles mínimos. Para enredar y deteriorar aún más la situación, el administrador de la hacienda de ese entonces fue asesinado por supuestos vínculos con grupos guerrilleros. Empezaron los asesinatos selectivos, como una forma de anunciar que las primeras autodefensas campesinas se estaban organizando en la región, mismas que con el pasar de los años se convertirían en grupos paramilitares con presencia en casi toda la Sierra Nevada, Parque Tairona, Zona Bananera y amplias regiones del Magdalena Grande.

De nuevo, en 1999 Cincinnati cambió de dueño y fue comprada por la familia Cianci Vega, quienes además adquirieron otras haciendas cafeteras como Vista Nieve, El Recuerdo y California, así como una tostadora de café en Santa Marta. Con esta movida, el negocio cafetero parecía que tomaba un nuevo impulso en la Sierra Nevada, pero problemas de diversa índole, como la presencia de grupos armados al margen de la ley o la judicialización de algunos

Campo, hija de Martín Salzedo Ramón, exgobernador y fundador de la hacienda Jirocasaca. 
propietarios de haciendas cafeteras, contribuyeron a que la producción del grano siguiera cayendo en la región.

La situación de orden público mejoró considerablemente en la Sierra Nevada a partir del año 2005, cuando se promulgó la Ley de Justicia y Paz que reglamentó la desmovilización de los grupos paramilitares en Colombia (Diario Oficial, 2005). El desmonte de los grupos paramilitares permitió que empezaran a llegar nuevas inversiones a la Sierra Nevada, para impulsar actividades como la caficultura y el turismo de naturaleza. Fue así como una de las familias tradicionales de Santa Marta, vinculada de tiempo atrás con el negocio del banano, incursionó en la economía cafetera. En efecto, en marzo de 2010, la familia Díaz Granados Guida compró la hacienda Cincinnati y de inmediato emprendió la renovación de los cafetales y la restauración de la Casa Grande. La familia no contaba con experiencia en el cultivo y exportación de café, pero la experiencia centenaria como cultivadores y exportadores de banano pudo facilitar la adaptación.

Al momento de la compra, la hacienda Cincinnati tenía 689 hectáreas y una plantación de 45.000 árboles de café, que ese primer año produjo cerca de 18.000 kilogramos de café seco pergamino. En 2018, la hacienda tenía sembradas 116 hectáreas de café y otras 509 hectáreas, que equivalían al $77 \%$ de la propiedad, estaban dedicadas a la conservación de los recursos naturales o reserva forestal (Cincinnati Coffee Co, s.f., p. 14). Ese mismo año, Cincinnati tuvo una producción récord de 120.000 kilogramos de café seco pergamino, contando con 35 empleados permanentes y 80 en época de cosecha. A nivel de comercialización, los propietarios hacían directamente las ventas a Alemania, donde tenían un único comprador ${ }^{12}$.

\footnotetext{
12 Visita a la hacienda Cincinnati y entrevista con José
} Ignacio y Juan Pablo Díaz Granados Guida, 19 de mayo

\section{B. Hacienda Jirocasaca}

La hacienda Jirocasaca está ubicada en la vertiente noroccidental de la Sierra Nevada de Santa Marta, en las proximidades del corregimiento de Bonda, Distrito de Santa Marta.

En 1868, el político y empresario samario Martín Salzedo Ramón adquirió un terreno de 406 hectáreas, y dos años después el gobierno le adjudicó un predio de 128 hectáreas denominado Jirocasaca. De inmediato, el exgobernador Salzedo Ramón sembró las primeras matas de café en su finca, que empezó a hacer de manera rigurosa para poder comercializar el grano en el mercado internacional (Flye, 1935, p. 27). En 1896, luego de tres décadas como propietario, las 534 hectáreas de Jirocasaca fueron vendidas por Salzedo al explorador francés G. Sogler (2017), quien a su turno negoció los terrenos dos años después con la francesa Sociedad de Plantaciones y Minas de la Sierra Nevada de Santa Marta.

A partir de 1898 se estructuró Jirocasaca como empresa, cuyo objetivo inicial fue la explotación de oro. Ante la escasez de la producción aurífera, los franceses se dedicaron a la siembra y la comercialización del café. En estos años (1896/98-1914) se estableció una organización vertical, que se sustentaba en profesionales franceses traídos a la hacienda. Así mismo, se construyó el campamento de los trabajadores y la Casa Grande que utilizaban los administradores de tiempo completo y los propietarios cuando visitaban la hacienda. También se instaló un sistema de aprovechamiento de aguas para generar energía y que la vez sirviera para el beneficio del café (Ramírez, 1987).

En el mismo período, los franceses acuñaron una moneda de circulación restringida, la cual podía ser cambiada por moneda nacional en las

de 2018. Entrevista con Juan Pablo Díaz Granados Guida, Santa Marta, 20 de marzo de 2019. 
oficinas administrativas de la finca en Santa Marta. De acuerdo con Machado, esta situación era frecuente en las grandes haciendas del país, donde los propietarios obligaban a los peones a comprar en las tiendas de la hacienda a precios más elevados (Machado, 1994, p. 44). Otra era la opinión del Ministerio de Industria al afirmar que, en el comisariato de la hacienda Jirocasaca, sus trabajadores encontraban toda clase de provisiones a precios convenientes (Ministerio de Industria, 1924, p. 230).

En los primeros años del siglo $\mathrm{XX}$, la hacienda llegó a tener una extensión de 2.184 hectáreas que se extendían desde los 150 metros hasta los
1.600 msnm, en la cima del cerro El Pueblito. Del total de hectáreas, 200 estaban dedicadas al cultivo del café, produciéndose un poco más de 560.000 kilogramos de café cereza $(45.000$ garrafones). Al estallar la Primera Guerra Mundial, los ingenieros y administrativos franceses debieron regresar a Francia a prestar el servicio militar obligatorio. La hacienda Jirocasaca la dejaron en manos del español Baldomero Gallegos, casado con la belga Olga Opdenbosch. En este período, el área de café aumentó a 234 hectáreas y la producción a 625.000 kilogramos de café cereza $(50.000$ garrafones), equivalentes a 143.000 kilogramos de café pergamino seco.

Cuadro 2

Extensión, producción y productividad de la hacienda Jirocasaca, 1898-1987

\begin{tabular}{|c|c|c|c|c|c|c|}
\hline \multirow[b]{2}{*}{ Período } & \multicolumn{2}{|c|}{ Extensión en hectáreas } & \multicolumn{3}{|c|}{ Producción de café } & \multirow[b]{2}{*}{$\begin{array}{l}\text { Productivi- } \\
\text { dad-kg/ha }\end{array}$} \\
\hline & Total & Cafetales & $\begin{array}{l}\text { Garrafon } \\
\text { es de } 25 \\
\text { lb }\end{array}$ & $\begin{array}{l}\text { Rendimien- } \\
\text { to }(\%)\end{array}$ & $\begin{array}{l}\text { Kg de café } \\
\text { pergamino }\end{array}$ & \\
\hline 1898-1914 & 2.184 & 200,75 & 45.000 & 23 & 129.000 & 642 \\
\hline 1914-1924 & 2.184 & 234,25 & 50.000 & 23 & 143.000 & 610 \\
\hline 1970-1971 & $1.477,5(1)$ & 234,25 & 72.000 & 28 & 253.920 & 1.084 \\
\hline $1973-1987$ & $1.477,5(1)$ & 234,25 & 54.600 & 26 & 210.000 & 896 \\
\hline
\end{tabular}

(1) Esta cifra resulta de sumar las 1.396 hectáreas que pertenecían a Guy Opdenbosch, con las 81,5 hectáreas que eran de los ocho parceleros independientes.

Fuente: Cálculos del autor con base en Ramírez (1987).

Luego de la muerte de Gallegos en 1924, la hacienda fue heredada por su viuda Olga Opdenbosch, quien, al no tener descendencia, invitó a su hermano Jorge para que le ayudara en la administración de Jirocasaca. En una primera etapa, que se extiende hasta mediados de los años sesenta, la producción de la finca decayó como consecuencia de la administración absentista que ejercía Olga y su hermano Jorge desde Bélgica y Santa Marta. Los hijos de Jorge, Georges y Guy, se vincularon con la administración de la hacienda a partir de la década de los sesenta. En efecto, en 1965, los hermanos Georges y Guy Opdenbosch constituyeron la Sociedad Hacienda Jirocasaca
Ltda. Lo más destacado en este período fue la parcelación voluntaria que los propietarios hicieron de su hacienda entre sus antiguos trabajadores, quienes lograron financiar sus parcelas con la Caja Agraria. El experimento de la parcelación se adelantó entre los años 1966 y 1971, tiempo durante el cual se capacitaron a los parceleros seleccionados, a quienes se les entregaron 16 lotes que sumaban 186 hectáreas sembradas de café. Los Opdenbosch se quedaron con seis lotes de 48 hectáreas en total ${ }^{13}$. Bajo el nuevo sistema de coadministración en el que las ganancias se distribuían de acuerdo a la producción por lote, luego de descontados los costos, se logró la mayor producción de la

13 Entrevista con los propietarios de la hacienda Jirocasaca, Guy y Gisselle Opdenbosch, Santa Marta, agosto de 1988 . 
hacienda desde su fundación: la cosecha 1970/1971 fue de 253.920 kilogramos de café pergamino.

En 1971 "Se rompe el sistema de coadministración bajo signos de desconfianza, se solicita la intervención de la Procuraduría Agraria y se inicia un proceso de deterioro de la parcelación" (Ramírez, 1987, p. 14). El proceso de parcelación se comenzó a revertir en 1973, año en que varios parceleros vendieron a los antiguos propietarios, logrando la familia Opdenbosch comprar 105 hectáreas que, sumadas a las 48 que conservaban del período de la parcelación, totalizaban 153 hectáreas en café. Todavía en 1987 ocho propietarios-parceleros con 82 hectáreas continuaban independientes de la hacienda. En los mismos años, el Incora parceló 700 hectáreas, por lo que el desmembramiento ascendió a 782 hectáreas.

En los años ochenta del siglo XX, la población que llegaba durante el período de cosecha era de unos 90 recolectores individuales y 15 familias (aproximadamente 45 personas), en las que el hombre podía ser recolector y la mujer fondera o cocinera. Si a esa cifra se le suma la población que trabajaba de forma permanente en la hacienda, la población total en época de cosecha podía superar las 230 personas entre adultos y niños.

Entre los años 1996 y 2002 se presentó la incursión de grupos armados ilegales en las diferentes vertientes de la Sierra Nevada. Ante la inseguridad imperante en la zona cafetera, los propietarios de Jirocasaca se vieron en la necesidad de administrar el negocio desde la distancia, lo que generó una decadencia en la producción y la productividad de la hacienda. En pleno período de crisis, en el año 2000, Guy Opdenbosch firmó un contrato asociativo con el Grupo Empresarial Daabón, el más poderoso de la ciudad, como una forma de asegurar la venta de la producción cafetera. Diferencias entre las

\footnotetext{
${ }^{14}$ Entrevista con Ana Margarita Vega Vives, viuda de Guy Opdenbosch. Santa Marta, 27 de marzo de 2019. Ana
}

partes hicieron que el acuerdo se rompiera en 2005.

En 2004 asumió la gerencia de Jirocasaca Ana Margarita Vega Vives, segunda esposa de Guy. En 2018, Jirocasaca tenía cerca de 200 hectáreas en cafetales, además de un lote en frutales (mango y naranja). Todavía se mantenían cinco parcelas independientes de la hacienda, que sumaban cerca de 50 hectáreas en café. Además de los cafetales y frutales, la hacienda Jirocasaca tenía dos reservas forestales constituidas con 330 hectáreas y otros terrenos que se fueron recuperando para la conservación. En total, la hacienda tiene, para el 2018, una extensión aproximada de 1.300 hectáreas distribuidas entre cafetales, reservas forestales, frutales, infraestructura vial y construcciones de viviendas y beneficio del café ${ }^{14}$.

\section{Hacienda La Victoria}

La hacienda La Victoria fue fundada en el año 1896 por la sociedad inglesa Libano Coffee Company. La Victoria está ubicada en la vertiente norte de la Sierra Nevada de Santa Marta, en la cuenca del río Gaira, distrito de Santa Marta, entre los 700 y $2.700 \mathrm{msnm}$. En 1897, el administrador William Crane contrató al norteamericano Orlando Flye como ingeniero de apoyo de esta empresa cafetera que apenas comenzaba. Para principios del siglo XX, la empresa seguía siendo de capital inglés y cambió de razón social por The Victoria Coffee Company Limited, siendo sus principales accionistas los ciudadanos ingleses Phillip $\mathrm{H}$. Marshall, gerente de la Compañía Ferrocarril de Santa Marta, y Ernest A. Olin. Por su parte, Alexander Koppel se desempeñaba como administrador. En 1929 se liquidó la mencionada empresa y fue constituida la Sociedad Cafetera de La Victoria, con los esposos Charles y Alice Bowden como accionistas mayoritarios. En los años 30, la hacienda tenía una extensión de 280 hectáreas,

Margarita es la gerente de la sociedad Amarvevi S. en C. S., propietaria de la hacienda Jirocasaca. 
de las cuales 120 hectáreas tenían café ${ }^{15}$. Para esa época, el grano no solo se cosechaba y beneficiaba en la finca, sino que además se trillaba y se empacaba, y luego se transportaba hasta el puerto de Santa Marta, por donde era despachado a los mercados internacionales.

A mediados del siglo XX llegaron Hans y Annemarie Weber, matrimonio alemán que se hizo cargo de la administración de La Victoria. Hans Weber había trabajado en la década de 1930 en la hacienda Planes, Tolima, donde adquirió no solamente la experiencia respecto al cultivo del café, sino que conoció la manera de trabajar del campesino tolimense. Durante la Segunda Guerra Mundial, Weber debió regresar a Alemania para de nuevo emprender viaje a Colombia, a donde llegó a comienzos de 1950. Pero esta vez su destino no estaba en el interior del país: los propietarios de la hacienda La Victoria, Alice y Charles Bowden, lo contrataron como administrador de su plantación cafetera ubicada en la vertiente norte de la Sierra Nevada de Santa Marta.

Entre 1950 y 1953, Hans hizo las veces de administrador y secretario de la hacienda, reservándose Charles Bowden el cargo de gerente de la empresa, función que ejercía desde Inglaterra. A principios de 1954, La Victoria se convirtió en propiedad de la familia Weber, inaugurándose una época de progreso y modernización de la caficultura de esta hacienda.

A la llegada de la familia Weber, La Victoria tenía alrededor de 230 hectáreas sembradas de café arábigo, muchas de ellas en estado de total abandono. Ante la dificultad de atender los cafetales en la forma adecuada, los propietarios tomaron la decisión de concentrar sus esfuerzos en las hectáreas de mayor productividad, disminuyéndose así el área en cafetales. En 1997, la hacienda tenía 140 hectáreas en café tradicional y 80 en variedad "caturra". De la extensión total de la finca calculada en 1.120 hectáreas, 220 se encontraban en café, 30 en potreros, más de 700 en reserva forestal, y el resto lo ocupaban las construcciones, los caminos y las zonas de rastrojos. La Victoria poseía una de las reservas forestales privadas más grandes de la Sierra Nevada, la cual actuaba como cordón protector de la parte media y alta de la cuenca del río Gaira.

Para la cosecha 1994/1995 se recogieron 58.000 latas de café uva; al año siguiente, la cosecha bajó a 20.000 latas; para 1996/1997 la producción se situó en 28.000 latas.

\section{Cuadro 3}

Hacienda La Victoria: producción de café y productividad por hectárea, 1994-1997

\begin{tabular}{|l|l|l|r|r|}
\hline Año cosecha & $\begin{array}{l}\text { No. de } \\
\text { latas }\end{array}$ & $\begin{array}{l}\text { Factor } \\
\text { multiplicador }\end{array}$ & $\begin{array}{l}\text { Producción kg } \\
\text { café pergamino }\end{array}$ & $\begin{array}{l}\text { Productividad } \\
\text { por hectárea }\end{array}$ \\
\hline $1994 / 1995$ & 58.000 & 3.7 & 214.600 & 975 \\
\hline $1995 / 1996$ & 20.000 & 3.7 & 74.000 & 336 \\
\hline $1996 / 1997$ & 30.000 & 3.7 & 111.000 & 505 \\
\hline
\end{tabular}

Fuente: Entrevista con Gabriel Rueda (Administrador-Mayordomo de la hacienda La Victoria), el 23 de junio de 1997. NOTA: De acuerdo con la misma fuente, una lata equivale a 12.5 kilogramos de café cereza aproximadamente y 3.7 kilogramos de café pergamino.

Es tradición que, en la Sierra Nevada, después de una buena cosecha, se caiga al año siguiente

15 Testimonio de Doris Rodríguez, subgerente de la Sociedad Cafetera de La Victoria, con base en la Escritura en una mala, luego se continúe a una regular, para volver al tercer año a una buena cosecha.

Pública $\mathrm{N}^{\circ} 1057$ del 22 de marzo de 1929, Notaría Cuarta de Bogotá. 
La producción media de la hacienda se puede calcular en 40.000 latas de café en uva por cosecha, resultando cerca de 148.000 kilogramos de café pergamino.

En cuanto a mano de obra, la hacienda llegó a tener entre 60 y 80 trabajadores permanentes hasta mediados del siglo XX. En la década de 1990 había 16 empleados de tiempo completo, entre los que se encontraban administrativos, servicios generales y obreros. Todos los trabajadores han contado con las prestaciones sociales que ordena la ley, además de otros servicios gratuitos que ofrece la hacienda como alojamiento con su dotación, energía, teléfono y agua potable.

En lo atinente a infraestructura física $\mathrm{La}$ Victoria es, tal vez, junto a Cincinnati y Jirocasaca, la hacienda cafetera mejor dotada de la Sierra Nevada. Además de la Casa Grande, cuenta con cabañas para huéspedes, casas para los trabajadores, campamento para los recolectores y sus familias, una microcentral hidroeléctrica (Pelton) con capacidad para generar 18 kilovatios de energía, suficiente para el consumo de la hacienda. Para diversificar el riesgo, están interconectados a los servicios ofrecidos por la empresa de energía.

A mediados del siglo XX, Weber no solamente beneficiaba, sino que además trillaba, empacaba y exportaba su propio producto a los mercados europeos. Sin embargo, desde hace varias décadas, la trilladora está en desuso y el café es vendido a las trilladoras ubicadas en Santa Marta.

Desde la llegada de la familia Weber, la administración de la hacienda estuvo en manos de sus propietarios: de 1950 a 1991 Hans Weber estuvo al frente de la Compañía Cafetera La Victoria Ltda., y su señora, Annemarie de Weber, hizo las veces de subgerente, desempeñando todas las actividades referidas a la administración de personal y contabilidad. Durante algunos años de la década de 1970, los Weber intentaron imitar el modelo de parcelación y la habrían puesto en práctica en la hacienda Jirocasaca como una forma de atenuar la problemática generada por la escasez de mano de obra, necesaria para la limpia de cafetales y la recolección de la cosecha. La experiencia fracasó y a los tres años se volvió al sistema directo de administración.

Después de la muerte de Hans Weber en 1991, su viuda Annemarie y su hijo Miguel comenzaron a reorganizar la administración de la hacienda para que esta continuara funcionando dentro de los parámetros empresariales. Entre 1991 y 2018, el gerente de la Compañía Cafetera de La Victoria Ltda. fue Miguel Weber, quien inicialmente ejerció sus responsabilidades desde México ${ }^{16}$.

Miguel nació en Alemania en 1946, apenas un año después de haber finalizado la Segunda Guerra Mundial, tras la derrota del Ejército Nazi ante las potencias aliadas. Cuando sus padres viajaron a Colombia en 1950 para hacerse cargo de la hacienda La Victoria, Micky apenas tenía cuatro años. Desde ese momento hasta cuarto de primaria hizo sus estudios en la propia finca, orientados por una institutriz contratada por sus padres. Luego fue llevado a Bogotá para estudiar en el Colegio Alemán y pasó más tarde al Colegio Alemán de Barranquilla. Una vez se graduó de bachiller, viajó a Alemania a estudiar en la universidad su carrera profesional. En 1970 se radicó en México donde hizo una carrera empresarial exitosa. Al morir su madre, y ante la amenaza real de que los paramilitares se quedaran con la hacienda, en el año 2002 Miguel Weber y su esposa Claudia decidieron retornar a La Victoria, dejando atrás las comodidades ofrecidas por su empresa en México. Eso sí, ante el peligro que implicaba establecerse en una zona dominada por la violencia paramilitar, Miguel y Claudia

${ }^{16}$ Visita a la hacienda La Victoria y entrevista con su gerente y propietario Miguel Weber, 25 de febrero de 2017. 
decidieron que sus dos hijos se quedaran en el exterior.

Al volver a la hacienda en el año 2002, encontraron que la Casa Grande de su hacienda estaba ocupada por jefes paramilitares. Ejerciendo su poder de convicción, Micky y Claudia empezaron a recuperar su hacienda, aunque viviendo momentos de gran tensión. De esa forma angustiante pasaron los Weber una primera etapa luego de su retorno a la hacienda, pero ese mismo año el Gobierno nacional inició un proceso de diálogo con los grupos paramilitares en Colombia, situación que se concretó en el 2005 con la desmovilización de estos grupos armados.

Este panorama de mayor seguridad y neutralización de los actores armados motivó a Miguel y a Claudia a emprender nuevos proyectos y a acelerar la renovación de los cafetales para aumentar la producción de la hacienda. La estrategia de los Weber se enfocó en diversificar la producción, como una forma de encontrar una fuente alterna de ingresos y no depender exclusivamente del café. En este intento han tenido éxitos y fracasos. Fue así como nació la idea de establecer una granja avícola para vender los huevos en el mercado regional, pero este proyecto nunca se concretó. También iniciaron un proyecto turístico con la adecuación de un museo del café en la propia hacienda, en donde también se vende el café tostado "La Victoria", como un valor agregado a la venta de café pergamino seco. Después del café, el turismo ha sido la actividad alterna más importante de La Victoria, con un flujo permanente de turistas que puede ascender a más de 5.000 visitantes al año ${ }^{17}$. El proyecto turístico también se compone de un hostal, desarrollado por unos jóvenes aventureros franceses, quienes compraron a los Weber el

\footnotetext{
${ }^{17}$ Entrevista con Claudia de Weber, gerente-propietaria de la hacienda La Victoria, Santa Marta, 27 de marzo de 2019.

${ }^{18}$ www.casasviejasminca.com
}

antiguo campamento donde dormían los recolectores de café. El campamento estaba integrado por dos casas campesinas que fueron restauradas y convertidas en Casas Viejas Hostel Lodge, inaugurado en diciembre de $2016^{18}$.

De otra parte, con unos socios externos incursionaron en el negocio de la cerveza artesanal, proporcionando el agua de los manantiales que nacen en la propia hacienda. Esta cerveza ha tenido un pequeño nicho de mercado en la ciudad de Santa Marta. Otro de los proyectos ha sido la venta de pequeños lotes para la construcción de cabañas turísticas ${ }^{19}$. Estos diversos proyectos han permitido que, desde los primeros años del siglo XXI, la hacienda La Victoria tuviera una producción diversificada y un flujo de caja que amortiguara las épocas de bajos precios del café.

La cosecha del 2018 fue de 38.000 kilogramos de café pergamino seco, inferior a la de años anteriores. Esta baja cosecha pudo estar asociada a problemas como el deterioro de la salud de su propietario, así como a los propios cafetales que, seis años atrás, habían tenido roya $^{20}$.

Miguel Weber murió en el 2018, por lo que su esposa Claudia quedó al frente del negocio cafetero, viviendo en la propia hacienda. Sus dos hijos están radicados en Alemania y México, pero son su apoyo en diferentes aspectos de la administración de la hacienda.

\section{Comentarios finales}

Desde la época en que Antonio de Narváez y La Torre reportó las primeras matas de café en la Sierra Nevada de Santa Marta, ha transcurrido un largo período de dos siglos y medio durante

\footnotetext{
${ }^{19}$ Visita a la hacienda La Victoria y entrevista con su gerente y propietario Miguel Weber, 25 de febrero de 2017.

${ }^{20}$ Entrevista con Claudia de Weber, gerente-propietaria de la hacienda La Victoria, Santa Marta, 27 de marzo de 2019.
} 
el cual la caficultura regional ha evolucionado lentamente, acorde con las características naturales que impone esta subregión.

A finales del siglo XIX se da una primera colonización cafetera en las vertientes norte y suroriental de la Sierra Nevada (municipios de Santa Marta y Valledupar) y Serranía del Perijá (municipio de Villanueva). Las haciendas que se establecieron en la cara norte de la Sierra Nevada llegaron a desarrollar un completo y complejo proceso en la industrialización del café: además de producir el grano, lo beneficiaban, trillaban, tostaban, empacaban y exportaban a los mercados internacionales, aunque esto último en pequeñas cantidades.

En las cercanías de Santa Marta, los cafetales eran cultivados en extensas plantaciones de hasta 700.000 arbustos, utilizando mano de obra básicamente santandereana, pero además atlanticense, tolimense, portorriqueña y jamaiquina. Por su parte, la mayoría de propietarios y administradores eran de origen europeo o norteamericano, destacándose la presencia de varios matrimonios al frente de la explotación cafetera. Los trabajadores de estas haciendas disponían de un salario más alto que sus similares del interior del país, producto de la competencia por mano de obra que ejercía la Zona Bananera de Santa Marta y más tarde los cultivos de marihuana (bonanza marimbera).

Luego de la segunda colonización adelantada a partir de la década de 1950 por campesinos andinos que huían de la violencia política del interior del país, se configuró el cinturón cafetero de la Sierra Nevada sin graves conflictos entre colonos y hacendados, pero sí con invasiones y conflictos con la propiedad comunal de los indígenas. Esta última problemática se agravó a partir de la década de 1970, con la irrupción de los cultivos comerciales de marihuana: violencia generalizada, deforestación, competencia por mano de obra y el subsecuente encarecimiento del jornal. La bonanza marimbera sacó de competencia a muchos caficultores tradicionales, quienes se vieron obligados a vender sus propiedades ante las dificultades económicas y problemas de seguridad: dentro de estas plantaciones cabe mencionar a Cincinnati, Vista de Nieve y El Recuerdo, para solo citar algunas.

A 2018, dos de las grandes haciendas de la vertiente norte como son Jirocasaca y La Victoria están viviendo una transición en su administración, ya que sus gerentes-herederos murieron hace poco tiempo: Guy Opdenbosch (2017) y Miguel Weber (2018). Jirocasaca quedó en manos de Ana Margarita Vega Vives, viuda de Guy, quien ahora se enfrenta sola a la administración de la hacienda. La Victoria está bajo la administración de Claudia de Weber, viuda de Miguel, quien cuenta con el apoyo de sus hijos desde el exterior. Por su parte, en 2010, la hacienda Cincinnati fue adquirida por los hermanos Díaz Granados Guida, empresarios de Santa Marta con amplia trayectoria en el cultivo y exportación de banano.

A esto se suma una positiva labor gerencial en los Comités Departamentales de Cafeteros del Magdalena y Cesar-Guajira, así como la destacada labor que vienen haciendo los cafeteros y directivos de la Cooperativa de Cafeteros de la Costa - Caficosta. Todo ha generado una dinámica positiva en la actividad y un ánimo de optimismo en la mayoría de los cafeteros de la Sierra Nevada de Santa Marta.

\section{Libros y Revistas}

\section{Referencias}

Banco de la República (1964). Atlas de Economía Colombiana (Cuarta Entrega: Aspectos Agropecuarios y su Fundamento Ecológico), Bogotá: Banco de la República.

Boardman, M. (1908). Coffee and Love Affair. An American Girl's Romance on a Coffee Plantation, New York: Frederick A. Stokes Company. 
Carriker, M. (2002). Vista Nieve. Bogotá: Federación Nacional de Cafeteros de Colombia.

Chalarca, J. (1998). Vida y hechos del café en Colombia. Bogotá: Común Presencia Editores.

Cincinnati Coffee Company (s.f.). Hacienda Cincinnati. Geographical and Historical Memory (folleto divulgativo), Santa Marta.

Comité Departamental de Cafeteros CesarGuajira (2019). Indicadores cafeteros Comité Cesar-Guajira, Presentación en Power Point, Valledupar.

Comité Departamental de Cafeteros Del Magdalena (2019). El Comité de Cafeteros del Magdalena y su razón de ser, Presentación en Power Point, Santa Marta.

Cooperativa Cafetera de la Costa - Caficosta (2018). El aroma y el sabor Caribe del café. Presentación en Prezzi, Santa Marta.

Dangond, J. (1990). De París a Villanueva, Memorias de un vallenato. Bogotá: Plaza y Janés Editores.

De La Rosa, J. (1945). Floresta de la Santa Iglesia Catedral de la Ciudad y Provincia de Santa Marta. Barranquilla: Biblioteca Departamental del Atlántico.

De Mier, J. (1975). Don Joaquín de Mier y Benítez. Bogotá: Editorial Kelly.

De Narvaez, A. y De Pombo, J. I. (1965). Escritos de dos economistas coloniales. Bogotá: Banco de la República.

FNCC - Federación Nacional de Cafeteros de Colombia (2018). Área cultivada con café según nivel de tecnificación por departamento. Estadísticas históricas.
Recuperado

de

Flye, O. (1935). Mis impresiones de la Sierra Nevada de Santa Marta. Revista PAN, 3, $27-32$.

Friede, J. (1963). Colonos alemanes en la Sierra Nevada de Santa Marta, Revista Colombiana de Antropología, XII, 403 411

Fundación Pro-Sierra Nevada De Santa Marta (1994). Bibliografía General de la Sierra Nevada de Santa Marta. Bogotá.

Goenaga, J. (1932). Colonización de la Sierra Nevada de Santa Marta (Fragmento de un Estudio sobre este Macizo). Santa Marta, Magdalena: Tipografía Pinto Robles.

Guhl, E. (1950). La Sierra Nevada de Santa Marta, Revista de la Academia Colombiana de Ciencias Exactas, Físicas y Naturales.

Julián, A. (1980). La Perla de América, Provincia de Santa Marta. Bogotá: Academia Colombiana de Historia.

Junguito, R. (1978). Economía Cafetera Colombiana. Bogotá: Fedesarrollo y Fondo Cultural Cafetero.

Krogzemis, J. (1967). A Historical Geography of the Santa Marta Area, Colombia, University of California, Berkeley, USA.

Le Moyne, A. (1969). Viaje y Estancia en la Nueva Granada. Bogotá: Ediciones Guadalupe.

Machado, A. (1994). El Café, de la Aparcería al Capitalismo. Bogotá: TM Editores.

Marichal, C. (2003). Teoría e historia de empresas. En: Guedea, V y Ludlow, L. El historiador frente a la historia. Historia 
económica de México. Ciudad de México: Universidad Nacional Autónoma de México.

Minagricultura - Ministerio de Agricultura y Desarrollo Rural (2016). Evaluaciones agropecuarias municipales. La Guajira: Agronet.

Ministerio De Industria (1924). Jirocasaca. Revista de Industrias, I (7).

Molano, A., Rozo, F., Escobar J. y Mendiola, O. (1988). Diagnóstico de la Sierra Nevada de Santa Marta. Area Social \#23: Aproximación a una Historia Oral de la Colonización de la Sierra Nevada de Santa Marta. Descripción Testimonial. Bogotá: Fundación Pro-Sierra Nevada de Santa Marta.

Monsalve, D. (1927). Colombia Cafetera Información General de la República y Estadísticas de la Industria del Café. Barcelona: Artes Gráficas.

Posada, E. (1993). Más allá de los Andes: las ramificaciones de la cultura cafetera en el Caribe Colombiano, 1850-1950. C.M.H.L.B. Caravelle, 61, 155-164.

Ramírez, J. (1987). Estudio de impacto ambiental de microcentral hidroeléctrica, planta de beneficiadero de café y planta de tratamiento de agua en la hacienda Jirocasaca. Mimeo, Santa Marta.

Reclus, E. (1992). Viaje a la Sierra Nevada de Santa Marta. Bogotá: Instituto Colombiano de Cultura - Colcultura.

Sociedad de Agricultores de Colombia - SAC. (1924). Reseña histórica de las labores ejecutadas por la S.A.C. en los 20 años de su existencia. Bogotá: Editorial Marconi.

Sogler, G. (2017). Exploración y colonización en la Sierra Nevada de Santa Marta. En:
Niño, J., Indios y Viajeros. Los viajes de Joseph de Brettes y Georges Sogler por el norte de Colombia 1892-1896. Bogotá: ICANH, Universidad de los Andes, Pontificia Universidad Javeriana.

Thevernin, E. (1924). Proyecto de Exploración a la Sierra Nevada de Santa Marta, con fines prácticos. Revista de Industrias, I (7).

Torres, E. (2003). Funciones empresariales, cambio institucional y desarrollo económico. En: Dávila, C. Empresas y empresarios en la historia de Colombia. Siglos XIX y XX. Una colección de estudios recientes, 2 tomos. Bogotá: Cepal-Editorial Norma-Universidad de los Andes.

Urrutia, M. y Arrubla, M. (1970). Compendio de estadísticas históricas de Colombia. Bogotá: Universidad Nacional de Colombia.

Viloria, J. (1998). Café Caribe: la economía cafetera en la Sierra Nevada de Santa Marta. Revista Cafetera de Colombia, 209, 53 - 94.

Viloria, J. (1998A). Aspectos históricos del café en la Sierra Nevada de Santa Marta. Historia Caribe, 3.

Viloria, J. (2014). Empresarios del Caribe colombiano: Historia económica y empresarial del Magdalena Grande y del Bajo Magdalena, 1870-1930. Bogotá: Banco de la República.

\section{Archivo, Prensa y Entrevistas}

Archivo Histórico del Magdalena Grande AHMG

Gobernación de la Provincia de Santa Marta, Juzgado de Bienes de Difuntos. Causa: 
"Mortuoria de don Pedro Cothiné", 18171819, folios 356-450.

Notaría Primera de Santa Marta, Testamento de don Pablo Oligós y nombramiento de su albacea doña Ana Teresa Díaz Granados de Oligós, febrero 27 de 1817.

Notaría Primera de Santa Marta, Escritura Pública $\mathrm{N}^{\circ}$ 38, 23 de mayo de 1892.

Notaría Segunda de Santa Marta, Escritura Pública $\mathrm{N}^{\circ}$ 41, 26 de febrero de 1943.

\section{Entrevistas}

Entrevista con los propietarios de la hacienda Jirocasaca, Guy y Gisselle Opdenbosch, Santa Marta, agosto de 1988.

Entrevista con el señor Jesús Balaguera, Santa Marta, 14 de mayo de 1997.

Entrevista con el señor Delfín Balaguera Jr., Santa Marta, 15 de mayo de 1997.

Entrevista con Beatriz Flye de Mitchell, Santa Marta, 20 de abril de 1997.

Entrevista con Paulina Flye de Escribano, Santa Marta, 20 de abril de 1997.

Entrevista con Doris Rodríguez, subgerente de la "Sociedad Cafetera de La Victoria", con base en la Escritura Pública $\mathrm{N}^{\circ} 1057$ del 22 de marzo de 1929, Notaría Cuarta de Bogotá, Santa Marta, 2 de junio de 1997.

Entrevista con Gabriel Rueda, administradormayordomo de la Hacienda La Victoria, el 23 de junio de 1997.
Visita a la hacienda La Victoria y entrevista con su gerente - propietario Miguel Weber, 25 de febrero de 2017.

Visita a la hacienda Cincinnati y entrevista con los socios de la empresa José Ignacio y Juan Pablo Díaz Granados Guida, 19 de mayo de 2018.

Entrevista con Juan Carlos García, Gerente de la Cooperativa Caficosta, Santa Marta, 18 de marzo de 2019.

Entrevista con Edgar Ramírez, Gerente del Comité de Cafeteros del Magdalena, Santa Marta, 19 de marzo de 2019.

Entrevista con Juan Pablo Díaz Granados Guida, socio de la Cincinnati Coffee Company, Santa Marta, 20 de marzo de 2019.

Entrevista con Ana Margarita Vega Vives (viuda de Guy Opdenbosch), gerentepropietaria de la hacienda Jorocasaca. Santa Marta, 27 de marzo de 2019.

Entrevista con Claudia de Weber (viuda de Miguel Weber), gerente-propietaria de la hacienda La Victoria, Santa Marta, 27 de marzo de 2019.

\section{Prensa}

El Estado, $\mathrm{N}^{\circ}$ 2548, Santa Marta, martes $21 \mathrm{de}$ junio de 1932.

El Espectador, Bogotá, sábado 27 de septiembre de 1969, p. 3A.

Diario Oficial, $\mathrm{N}^{\circ}$ 45.980, Ley 975 de 2005 (Ley de Justicia y Paz), Bogotá: Congreso de la República. 